-Editorial

\title{
Toward the brain matrix of pain
}

\author{
Jun CHEN ${ }^{1,2}$
}

${ }^{1}$ Institute for Biomedical Sciences of Pain and Institute for Functional Brain Disorders, Tangdu Hospital, The Fourth Military Medical University, Xi'an 710038, China

${ }^{2}$ Institute for Biomedical Sciences of Pain, Capital Medical University, Beijing 100069, China

\section{Changing the definition of pain}

Pain was officially defined by International Association for the Study of Pain (IASP) as "an unpleasant sensory and emotional experience associated with actual or potential tissue damage, or described in terms of such damage" $[1]$. Although this scientific definition of pain helps scientists a lot to study nociceptive mechanisms at peripheral and spinal levels, it is obscure somewhat for clinicians who are coping with pain problems because it is sometimes impossible to link the pain of patients with any tissue injury on the body such as headache, abdomen ache and some chronic pain states. Thus the concept or definition of pain is required to be changed with the emergence of translational science from bench to bedside. The IASP's definition of pain has been challenged by D.D. Price who proposed a new definition of pain as "a somatic perception containing (1) a bodily sensation with qualities like those reported during tissue-damaging stimulation, (2) an experienced threat associated with this sensation, and (3) a feeling of unpleasantness or other negative emotion based on this experienced threat" ${ }^{\prime 2]}$. The new definition proposed by D.D. Price has great significance: (1) patients and clinicians do not need to directly demonstrate an association between biologically tissue damage and the sensation of pain; (2) highlighting the roles of the brain dysfunctions in chronic pain that might be caused by previously experienced tissue damage of a part or parts of the body that may not presently exist in chronic pain patients. However, this change in pain idea requires a more dynamic shift of research work from spinal level toward the brain matrix of pain.

\section{Understanding the brain matrix of pain}

There are tremendous amounts of brain imaging studies in both human and animal subjects supporting that pain is a complex experience consisting of sensory-discriminative, affective-motivational, and cognitive-evaluative dimensions ${ }^{[2-3]}$. Now it has been gradually known that noxious information caused by tissue or nerve damage is processed by a widelydistributed, hierarchically-interconnected neural network, referred to as neuromatrix, in the brain (Fig.1) ${ }^{[3-4]}$. Therefore, understanding of chronic pain as a multidimensional experience requires more studies on the inherent characteristics between pain experience and structural or functional state of the brain matrix. However, looking back to the past 44 years since the appearance of the gate-control theory of pain proposed by R. Melzack and P.D. Wall (1965), identifying multiple neural networks subserving these functional aspects of pain and use of this knowledge to manipulate the pains in clinic in new and beneficial ways is still a challenging task. There is now a consensus on the idea that pain, when becomes persistent or chronic, may cause not only sensory dysfunction (spontaneous pain, hyperalgesia and allodynia), but also various functional brain disorders such as anxiety, loss of sleep, amnesia, and depression ${ }^{[5]}$. These co-morbidities of chronic pain make it necessary to extend the pain research from lower levels of the 'pain matrix' into the higher level of cortical and subcortical brain structures ${ }^{[6,7]}$. 


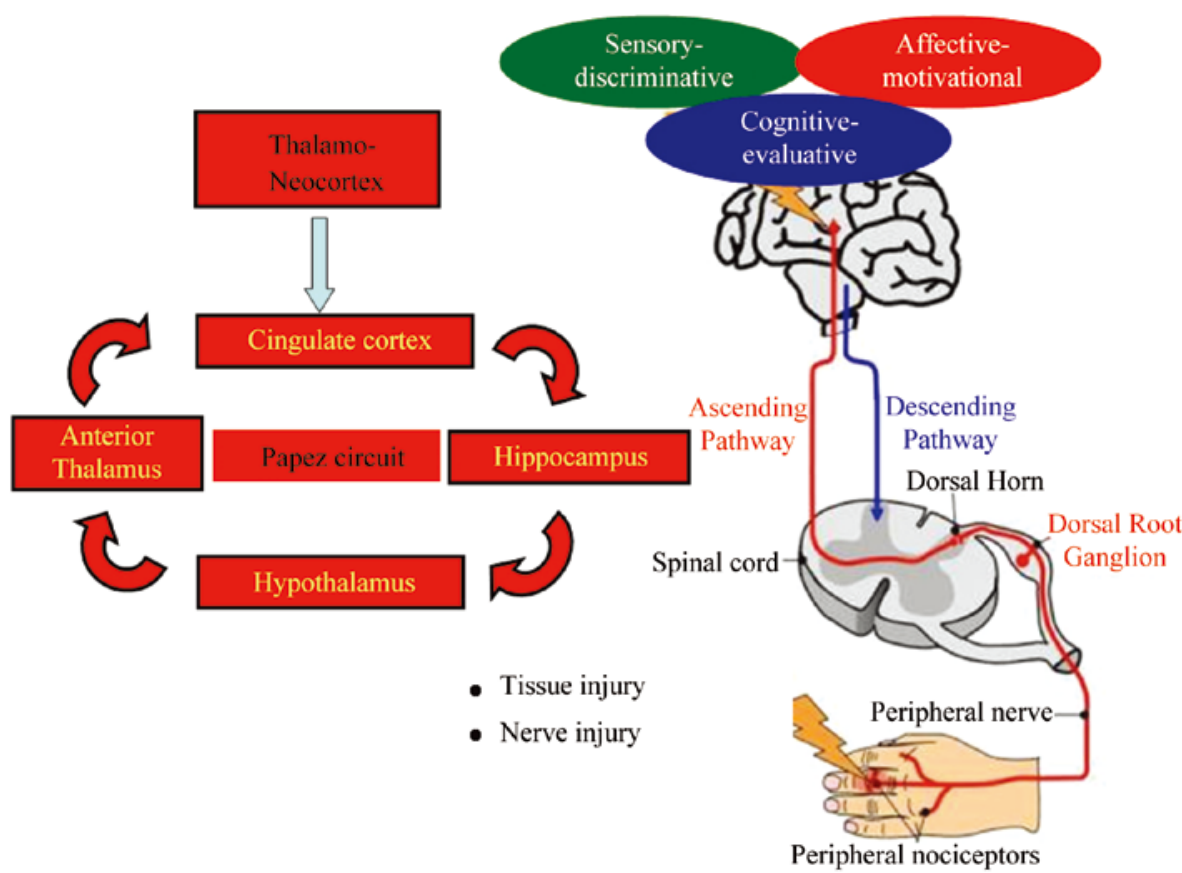

Fig. 1 A scheme showing sensory-discriminative, affective-motivational, and cognitive-evaluative dimensions of pain produced at the cortical level driven by nociceptive information generated by peripheral tissue or nerve injury on the dorsum of a hand (right). The red line indicates the ascending pain pathway to the thalamo-cerebral cortex via synaptic relay at the spinal dorsal horn that are connected to the central terminals of the primary sensory neurons which use their peripheral nerve free endings innervating the skin. The blue line indicate descending pain modulation system originated from the cortico-brain stem pathway. On the left, an anatomical link between somatosensory cortex and limbic system proposed by Papez in 1937 that may underlie multiple dimensions of pain.

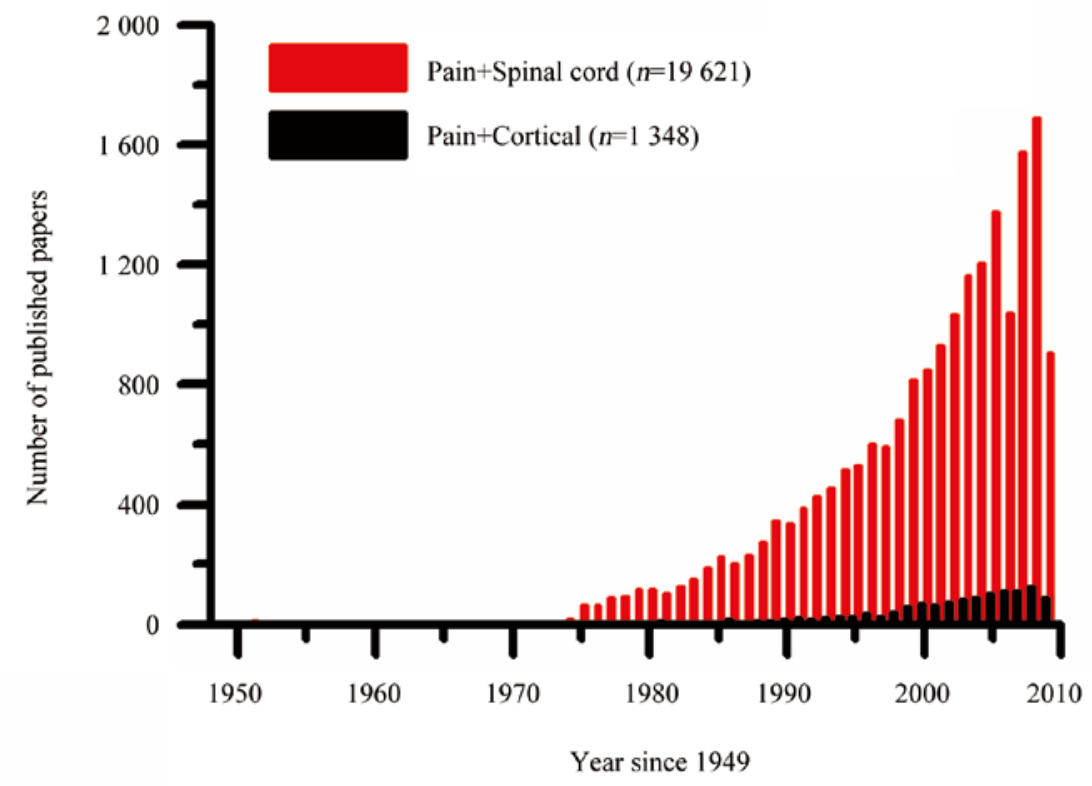

Fig. 2 An ISI website data showing the number of published scientific papers associated with the item "pain and spinal cord" or "pain and cortical" in the past sixty years (1949-2009) indicating a tremendous gap between the knowledge of spinal nociception and pain perception, emotion and cognition. 
However, the knowledge of pain perception, emotion and cognition is surprisingly poor and requires to be gained by experimental research using multiple approaches at the cortical levels (Fig. 2) ${ }^{[8]}$. Moreover, it is also widely aware that the therapeutic strategies of pain in clinic are more underdeveloped than other areas due to lack of knowledge in the aforementioned comorbidities of pain.

To stimulate the shift of scientific research toward the brain matrix of pain and to promote the development of research in the functions and dysfunctions of cerebral cortex associated with pain processing and modulation, a topical symposium on "Pain and Cortical Plasticity" will be organized by the Chinese Society for Neuroscience (CSfN) Sensory and Motor Subcommittee. The event is going to occur at the 8th CSfN Biennial Conference to be held in Guangzhou during November 7-10, 2009. The current special issue on "Pain and Cortical Plasticity" published in Neuroscience Bulletin, the official journal of the CSfN, will play a very important role in the opening of the field in the future.

\section{References:}

[1] Merskey H, Bogduk N. Classification of pain. $2^{\text {nd }}$ ed. Seattle: IASP Press 1994, p210.

[2] Price DD. Psychological mechanisms of pain and analgesia. Seattle: IASP Press 1999, p1-248.

[3] Casey KL, Bushnell MC. Pain imaging. Seattle: IASP Press 2000, p1-248.

[4] Melzack R. The future of pain. Nat Rev Drug Discov 2008, 7: 629.

[5] Crombie IK, Croft PR, Linton SJ, LeResche L, Von Korff M. Epidemiology of pain. Seattle: IASP Press 1999, p1-321.

[6] Liu MG, Chen J. Roles of the hippocampal formation in pain information processing. Neurosci Bull 2009, 25(5): $237-266$.

[7] Zhuo M. Cortical excitation and chronic pain. Trends Neurosci 2008, 31: 199-207.

[8] Merskey HM, Loeser JD, Dubner R. The paths of pain: 1975-2005. Seattle: IASP Press 2005, p1-549. 